\title{
IMMIGRATION AND EMIGRATION: CANADIAN AND MEXICAN YOUTH MAKING SENSE OF A GLOBALIZATION ISSUE
}

This is an Accepted Manuscript of an article published by Taylor \& Francis:

Nieto, Diego, \& Bickmore, Kathy. (2017). Immigration and emigration: Canadian and Mexican youth

making sense of a globalized conflict. Curriculum Inquiry, 47(1), 36-49, DOI: 10.1080/03626784.2016.1255934

\author{
Diego Nieto \\ diego.nietosachica@mail.utoronto.ca
}

Doctoral student, Curriculum Studies and Teaching Development

Comparative, International and Development Education, OISE

Professor, Universidad Icesi

Cali, Colombia

Kathy Bickmore

k.bickmore@utoronto.ca

Professor, Curriculum Teaching \& Learning,

Comparative International Development Education, OISE

Ontario Institute for Studies in Education, University of Toronto

252 Bloor Street West

Toronto, Ontario M5S1V6 Canada 


\title{
IMMIGRATION AND EMIGRATION: CANADIAN AND MEXICAN YOUTH MAKING SENSE OF A GLOBALIZATION ISSUE
}

\begin{abstract}
This paper discusses findings from focus groups with youth who attend schools located in underprivileged surroundings in one large multicultural city in Canada and in a moderately large city in México, examining their understandings and lived experiences of migration-related conflicts. In the Canadian context, participants framed these conflicts as a problem of racist attitudes towards immigrants in an otherwise welcoming city. In the Mexican context, emigration was understood as a questionable individual dream to overcome precarious economic conditions, which often brings about violence to those travelling and family fractures for those who stay. We identify the tensions between these dominant narratives about issues of transnational mobility usually also present in intended curriculum- and students' first-hand, every day, local-globalized citizenship experiences with ('in' and 'out') migration in each setting. In addition, we examine youths' own imaginaries of citizenship, contrasting the sense of agency and identity positions they express in each of these differently situated but structurally connected contexts in the global pattern of migration. In doing so, this work shows the limited opportunities youth have to make sense of their lived (globalized) conflicts beyond their own localized cultural explanations. We argue that connecting the recognition of cultural differences and positions in the world with the power imbalances and historically structured global inequities revealed by issues such as migration is crucial for educational efforts in citizenship education on global issues.

Migration is a window into the concrete realities of globalization - including conflicts between those who move and those who stay, competition for employment, movement of capital in search of cheap labor, and struggles for citizenship. Dominant discourses of mobility and education are epitomized by demands for global knowledge economy capabilities and by depoliticized notions of humanitarian ethics. However, young people's actual political, economic, and socio-cultural concerns and experiences of transnational mobility vary from place to place, revealing tensions with the usual intended school curriculum explaining this globalized world.

In this paper, we explore how understandings of global mobility take different shape for youth in underprivileged spaces in urban Canada (global North, receiving immigrants) and México (global South, sending emigrants). Comparing the ways these youth locate themselves in relation to their actual experiences with migration - a shared global event, linked with important social conflicts in both contexts-, we argue, reveals something of how they imagine their own and others' citizenship in the face of transnational phenomena. This allows us to localize the experience of globalization in relation to specific spaces of citizenship, and thereby to challenge typical curriculum notions of globalization driven by hegemonic economic or cosmopolitan goals.
\end{abstract}

\section{Localizing social conflicts and citizenship curricula through migration}

Citizenship reflects the relationship of individuals and groups, often mediated by the state, to ideals as well as actual processes for collective decision-making, justice, and inclusion/ belonging to a political community (Gordon, Long, \& Fellin, 2015). These citizenship practices and ideals, relations and institutions may open or impede opportunities to deal with social conflicts through democratic processes that help building sustainable peace. Democratic peacebuilding (Bickmore, 2015; Galtung, 1996) would mean in this case that, when disputes related to pressing migratory issues emerge - for instance around labor exploitation, refugee 
status, anti-immigrant expressions - , there exist opportunities to redress the structural and cultural roots of these social conflicts, and not simply mechanisms to enforce the absence of direct violence through repressive measures of population control.

Whereas dominant liberal democratic theory assumes that justice and therefore sustainable peace can be achieved by ignoring social differences and individualizing disputes, our research is based on the understanding that justice, therefore peace, requires recognizing and responding to the unequal structural positioning, attached to cultural and epistemological marginalization of specific social groups across borders (Young, 2007). That is to say, we share Santos (2001, p. 189) assertion that globalization processes entail localization, where power relations give some entities privileged positions in structures of transnational processes, sustained by means of their capacity to designate -culturally and epistemologically-a rival social condition or entity as local.

From this starting point, any analysis of citizenship curriculum with regards to globalization processes such as migration, must address the ways in which school curriculum contributes to these processes of localization: the ways in which different actors are placed and take up different positions in transnational structures of power. Accordingly, our research examines the particular globalization through educational processes of some localized youth in relation to a relevant local/globalized social conflict - migration, in contexts differently positioned in the structures of the global system.

We turn away, consequently, from most peace/conflict/citizenship education, which prescribes solutions that assume the superiority of Northern expert knowledge disconnected from the lived concerns and understandings embedded in any community (Lederach, 2003). Similarly, this approach contests western neoliberal ideas about citizenship and peace/conflict which, despite enormous differences in social realities, have spread globally in curricula, overlooking the varied local-global scales and historical roots of social conflicts and migration processes (Meyer, Bromley, \& Ramirez, 2010; Salomon \& Nevo, 2002).

This project focuses on student's relation to school curriculum on citizenship education and social conflicts, including intended content and pedagogy, and the implicit (modeled and practiced) social relationships and ideological perspectives embedded in what is and is not taught (Aoki, 2012; Apple, 1979). In that respect, research shows that school curricula on citizenship in Canada and México has not successfully addressed widespread political disengagement and social conflicts or violence (Cox, Bascopé, Castillo, Miranda, \& Bonhomme, 2014; Hughes, Print, \& Sears, 2010). In Mexican schools, institutional pressure to transmit large amounts of information often "prevents inclusion of the students' experience and imposes contexts" of affluent classes to marginalized youth (Tibbitts \& Torney-Purta, 1999, p. 17). Implemented citizenship curricula in Canada often emphasize formal civic structures or de-politicized individual behavior such as environmental care or charitable aid (Chareka \& Sears, 2005; Llewellyn \& Westheimer, 2009); marginalized youth may also juxtapose a contradictory sense that people like themselves may be at fault, seeing themselves as "bad" citizens (Kennelly \& Dillabough, 2008; Tupper \& Cappello, 2012). Thus there is an apparent mismatch between the citizenship usually taught in schools and that actually lived by many young people.

\section{Underprivileged Spaces and Migration Dynamics}

The Peace-Building Citizenship Learning project, from which this paper stems, focuses on said mismatch as it is expressed in underprivileged spaces of urban settings. Participant schools' neighborhoods in both contexts suffer of economic marginalization when compared to 
their surroundings, which comes along with class, race and cultural-related stigmatization due to crime rates and incidents involving gang and other types of violence. This is not uncommon in many cities of the globe, in which spaces of marginalization coexist with affluent sectors. However, it is important to recognize that lived citizenship experiences are radically different for youth inhabiting marginalized areas of cities.

Taking these factors into consideration, the project explores the actual expressions of the lived citizenship experiences of youth (age 10-15, grades 5 to 9) in such contexts, by discussing with them -and their teachers- various social conflicts they identify as relevant in their lives. It aims to open up opportunities to learn about potential peace-building citizenship actions in their schools: three elementary and intermediate public schools in a large multicultural city in Ontario, Canada and four in a moderately large city in Guanajuato, México.

During focus groups, participants identified a variety of social conflicts affecting their lives. In Ontario schools, for instance, students showed concern with sexual and racial discrimination (particularly islamophobia), bullying and cyber-bullying, and poverty and homelessness. In Guanajuato, issues such as domestic and gender-based violence, drug-related trafficking and violence, pollution, bullying, and authorities' abuse of power (police violence and state corruption) were of particular interest for students. Significantly, in both contexts, it was common for participants to discuss migration issues at some length, showing how relevant it is for youth in these underprivileged areas.

This comparative finding drew our attention to the importance of connecting local expressions of conflicts with transnational dynamics; voiced citizenship practices and ideals with people's movement across borders. In fact, migration has played a central role in the history of each of these spaces. In participating Canadian schools, students represented a great variety of racial and ethnic backgrounds -Caucasian, Black (usually West Indian or North African), Tamil, Middle Eastern, South Asian, Caribbean and Latino, Roma-Hungarian- expressive of urban Canada's historical and contemporary waves of immigration. In Guanajuato, while the experience of transnational immigration was hardly present in these schools -rendering classrooms ethnically and racially homogenous for the most part- their neighborhoods, too, had been shaped by historical processes of population mobility. Domestic rural-urban migrations, working class settlements growing around industrial factories, rural borders progressively coopted by urban expansion. More recently, a prominent issue has been the constant flow of people towards the "North" in search of opportunities.

In what follows, we present and compare the exchanges in each location that focused specifically on migration-related conflicts. It extracts findings from one (60-70 minute) focus group discussion each with 3-6 groups of about 5 students per school, in Ontario and Guanajuato - animated by visual prompts representing diverse instances of social conflict relevant to each context, thus, aiming to root our research in their first-hand, every day, localglobalized citizenship learning experiences.

\section{Making Sense of Migration as a (Lived) Social Conflict}

First, we discuss youths' understandings of the causes, actors, and social conflict processes involved in migration, and some relevant experiences they narrate, in order to contrast the characteristic ways in which transnational migration was lived in each setting.

\section{Ontario: Anti-immigrant expressions as racism}


The student participants in Ontario, a receiving context for migrants, consistently framed migration as a cultural conflict in which the arrival of migrants awakens racist rejection from some Canadians.

[Facilitator asks students to comment on an image of a 'Go Back to Where You Came From'sign]

Group $1 \mathrm{~A}^{1}$

S5Mg7 [Black West Indian]: Deportation, maybe.

S2Mg7 [Middle Eastern]: Racism.

S1Mg7 [White]: Like, people aren't getting the respect that they deserve, when they are not native to Canada; they are immigrants from countries that don't have the same rights.

Group 2A

$\mathrm{S} 1 \mathrm{M}$ [South Asian]: It is basically racism - against Islam and Muslims [peers agree]

S2M [South Asian]: And immigrants.

The students easily identified specific populations who suffered bias after arrival in Canada. They added that these newcomers were sometimes bullied in school, based on their ostensible limited competence in English or in Canadian cultural norms.

Group 3D

S2Fg6 [North African]: people new to this country do not know much English or do not know how to behave.

S5Mg5 [Black West Indian]: People from other countries don't know how to behave, so they might get bullied ...

S2Fg6 [North African]: ... once [a student from Syria] got here: she got bullied...

For these students, the causes of migration - apparently as they were taught in schoolare disease, discrimination, dictatorship and war in other places, which make people seek refuge in Canada.

Group 1D

S3Fg6 [Black West Indian]: We were just working [in class] on why people come to Canada: because there are different diseases, or maybe because there's Taliban. There are problems why people are running away from their own countries.

Group 2B

S4F5g6: Canada is a pretty safe place

S3F5g6: Unless the terrorists come here.

Group 3D

\footnotetext{
${ }^{1}$ In codes, letters refer to focus groups (A, B, C, D...) within numbered school sites $(1,2,3 \ldots)$. Students are $\mathrm{S}$ (Canada) or E (México)\#, female or male, and grade\#. When relevant and possible, we have also included racial or ethnic background and school grade, based on field notes (students did not necessarily self-identify, and in Mexico there were essentially no evident ethnic/ racial differences).
} 
S4Mg6 [Latino]: [We recently had a whole unit] about refugees. We found out the many countries they went through,- - Turkey, Hungary, Iraq - and people didn't want to let them through.

These students embraced the dominant image of their country and city as a secure place where multiculturalism is lived and defended, where discrimination against migrants is limited. Almost simultaneously but in contrast, some students spoke of relatives suffering unfair treatment.

Group 2A

S5F [South Asian]: Everyone isn't treated equally, cuz if you look at our community it's [a] very stereotyped multicultural community... We have people from all over the world in one place.

S2M [South Asian]: ... I've seen, like, my aunt came two years ago and was not always treated well.

Group 3B

S4M [Central Asian]: Some of the people in my family have been criticized because of skin color and where they are from.

Above, students share experiences that migrants in Ontario suffer racism, while reiterating the prevailing narrative that this should be condemned. At the same time, one of the schools had a significant population of Hungarian Roma youth (among many global migrants), singled out in the school as particularly troublesome. Some students there recognized that stereotypes emerged due to past experiences of cultural dissonance between newcomer and other populations. Others blamed patterns of victimization on these migrants' (perceived) bad behavior.

Group 3D

S1Mg6 [South Asian]: In our school, ... almost every Hungarian we see, they would cause a fight. So, every time a Hungarian came, people were biased against them.... [However] Once I met a Hungarian. I thought, he is going to be mean ... When I started to talk to him I realized, he is so nice ... taking away all [my] stereotypes against Hungarians.

Group 3E

[Facilitator: Does anti-immigration racism happen in your life?]

S3F5g6 [East Asian]: Some people.

S1M5g6 [Black]: Yeah

S2M5g6 [White]: A little bit.

S3F5g6 [East Asian]: Like Syrians.

S1M5g6 [Black]: Like Hungarians. People say to them, 'go back to your country.' S5F5g6 [East Asian]: Because most of the Hungarian are trouble makers.

S3F5g6 [East Asian]: They say bad words to you. ... They do not keep their money... They just ... waste all their money.

S1M5g6 [Black]: Exactly ...

S2M5g6 [White]: It is not completely their fault that ...they cannot afford good

food. They can only afford sugar food or junk food. So they are always hyper. 
S4M5g6 [South Asian]: Some people, they just do not like them when they first see them. So they just start to bother Hungarians that were mean to them. I know a kid got bullied who was Hungarian, but he did not do anything wrong.... S5F5g6 [East Asian]: Because they ... do not speak English yet. They just think they can do whatever they want, because they do not understand Canada ... Since they do whatever they want, other people say, 'you're just driving people crazy, just get back home.'

Thus, while many students were quick to identify the racist character of anti-immigrant expressions in abstract terms, reiterating a dominant narrative in their multicultural context, they rarely connected migration with structural inequities in their surroundings or the global system.

Many Ontario students struggled, moreover, to make sense of a cartoon depicting global economic inequality (pits excavated from southern continents, piled on northern continents). A few mentioned, in other instances, that immigrants might face poverty or difficulties finding employment, but such statements were scarce compared to their condemnation of racist attitudes: the prevalent understanding was that migration-related conflicts were rooted in people's (mistaken) beliefs and biases, not linked to structural processes and inequities.

In sum, participating Ontario students' understandings of migration were based on cultural explanations - (un)acceptable attitudes by a 'We' toward 'Others.' They also tended to root the causes of migration at a distance, not viewing themselves or the places they inhabit as participants in the reproduction of unequal-structural patterns of migration. This reinforces idealized views of Canada as welcoming and safe, even when contradicting some of the students' own experiences of transnationality.

\section{Guanajuato: Emigrating in search of individual dreams}

In apparent contrast to Ontario youth's cultural understandings of immigration, in Guanajuato (México) student participants connected migration with economic problems: the search for work opportunities and improved living conditions. Most had experienced this conflict directly: in almost all focus groups, multiple students mentioned close relatives and parents who had migrated North in search of adequately paid work or to reach the dream of a better future.

Group 1F

[Facilitator, showing a cartoon of a Mexican confronting a wall with McDonalds window and US flag: What is this conflict about?]

E3Fg7: You can see Mexicans trying to cross the border for a good job. Better paid. To send [money] to their families.

Group 2A

[Facilitator: Do you know people who have gone to the North?]

E5Mg4: My dad left with my uncle.

E4Fg6: My uncles and aunts.

E1Mg5: My siblings.

E5Mg4: My brother wants to leave but my dad does not want to let him go...

E2Fg5: Yes, a boy said his uncle had gone because he had no money and was sending money to his mother. 
The lived reality of these students, as of many others in the global South, is that it is almost normal that people leave the country: these fractures are a common part of their lives. Guanajuato students identified two ways emigration patterns represented violence. First, it left them abandoned by parents or close relatives: the bad material conditions and under-employment their parents endured in Guanajuato obliged them to travel. Second, students told they knew that the promise of a better future via migration quickly turned into a nightmare, because of the risks involved in illegally entering or as exploited workers in another country.

Group 1D

[Facilitator: Why is [migration] a problem?]

E5Fg7: That they abandon us ... It's a family problem...

Group 1F

[Facilitator: Do you know many people who have gone North?]

E5Fg7: Many people, and even more from here, but we know that they don't

make it: they are exploited, the migra [immigration police] catches them, also the mara [criminal gangs], women get raped and mistreated, and men get everything they have taken away and get killed. ... A friend, he left about a year ago because of lacking money, but he tells me they are treated very ugly...

E1Fg7: My uncle says he's doing very badly: they don't let them out and pay little.

[Peers tell similar stories]

Group 3C

E1Mg5: Many choose to go for a better quality of life and a better economy. People prefer to go to the US to find jobs, but what usually happens is that they end up working as waiters or farmers, so [the Americans] don't have to do that work. They work hard but the minimum wage is low.

Students reported that emigration had been mentioned in Geography, Spanish, or Civics/Ethics classes, and that teachers warned them of the dangers involved for those who dared to take this path, arguing that it was better to stay in school in Guanajuato. Group 1E

E1Fg8: We learned about migration of Mexicans to the US to seek a better economy for their family, and there was discrimination because they were called Indians, or they were kicked out, or sometimes, when they were crossing the border, they died from hunger and cold.

Group 2B

E1Mg4: Migration is talked about in the History book....

E2Fg6: The teacher told us that when they go somewhere else it's because they cannot get any job, and when they are on their way to the other country they can get killed ... In the Civics and Ethics book we learned that Mexico is considered a country that expels migrants. Many leave for lack of employment, or to study another language. 
Significantly, when considering the causes of migration conflicts, Guanajuato participants pointed to economic patterns such as low salaries and unemployment. However, when they identified potential mitigating actions, they emphasized (like Ontario participants) cultural patterns of individual behavior. They viewed the problem as rooted in individuals' attitudes towards money, success, and schooling, more than in the economic imbalances suffered within their own context and in the global economy.

\section{(Dis)Empowered Subjects' Imaginaries of Citizenship}

Students' understandings of social conflicts reveal ways in which globalization is experienced in their own lives given the specific positions they occupy in these processes. Youth's views of social conflicts also reveal their ethical-political judgments (what they consider fair or good), and their own sense of responsibility and agency with regard to such issues. As we have seen, although most students recognized structural patterns of inequity and harm, they often replicated dominant narratives of 'cultural blame' regarding migration, even contradicting some of their own lived experiences. These narratives hint at how they imagine citizenship and identity, revealing connections and tensions between their ways of being in the world and their sense of agency and belonging in a political community.

\section{Ontario: The welcoming multicultural imaginary}

As Ontario students, in their multicultural urban setting, condemned racist anti-immigrant attitudes, they express their own ideals about good citizens. For them, 'We' - Canadians - have a duty to welcome those who arrive, regardless of their race or national origin.

Group 1C

S3Fg6: [This city] is like: there's tons of different people, and you can never just assume that there's a person and they are just one thing. ... And, you know, you have all types of different stuff in your blood. So ... there's a whole bunch of different types of religions and stuff in Canada. It's not fair that you just deny a few people and let the other ones come.

\section{Group 3A}

S3Fg5 [East Asian]: Canada is a country of different cultures.... I'm sure half of Canada welcomes other countries. There are millions of refugees coming to Canada ... They should be welcome to come to Canada.

In addition, these young Ontarians exhibited a sense of agency to do something about anti-immigrant attitudes. They said people should speak up against racism, or organize campaigns to help newcomer refugees accommodate into Canadian society. Similarly, some said "positive encounters" with unfamiliar others could be a great opportunity that they would enjoy, to unlearn biases.

Group 3A

S5Fg6 [White]: [I heard on the radio about]... a small town where Syrians [refugees] came and [a woman] asked everyone in the town to come and meet them. She is just a regular person (mom) with two children that can help Syrians feel welcome.

S3Fg5 [East Asian]: Most of this [conflict] is happening because of miscommunication, and what we could do is have people from different religions 
and stereotypes have discussions about those issues or rights and [develop]

mutual understanding or respect....

S5Fg6 [White]: I think it would be nice to meet [recent immigrants] and learn

about their families too...

Group 3D

S4Mg6 [Latino]: You do not know what [Hungarian students] have gone through; their parents treat them bad... [So] make friends and ask them if something bothers them.

Ontario youth were critical of those who "do not understand that everybody is equal and should be welcomed." Thus they reproduced the imaginary of Canada as a welcoming multicultural nation and advocate a humanitarian cosmopolitan duty to help those in need, without analyzing critically the power relations, structural positions and historical roots of the conflicts involved. Decisions to help were framed as free choices based on a private belief, but separated from political obligations stemming from shared history, systemic global relationships, or their own participation in perpetuation of those problems.

Ontario students' identification as Canadians frames themselves as the center of acceptance and tolerance of the 'Other' - embracing the privileged (white) Western cosmopolitan imaginary even when contradicting their own racialized local positions and life experiences. They critiqued related contradictions in their experienced curriculum. They questioned the priority of studying war, slavery and other world issues always at a distance and in the past, without having opportunities to discuss and understand how conflicts happen and are handled locally and in the present, such that they could feel they could do something about them.

Group 3A

S5Fg6 [White]: We have actually talked about [immigration] a lot ... especially during the election with Justin Trudeau... But I kind of wish we would still talk about it a little bit more... it's an ongoing topic....

S3Fg5 [East Asian]: Right now [in class] we are doing a project about conflict. People are thinking about war... [We] talked about Syrian refugees, we also talked about bullying, but I wish we kind of talked about conflicts. Because when [the teacher] talked about conflicts, they weren't small conflicts in the world; they do matter....

S2Mg6 [White]: No one really focuses on conflicts that happen in the community, which is definitely important.

\section{Group 1D}

S2Fg6 [Black]: I wish in school we could sometimes talk about ... stuff that happens, even stuff like racism and homophobia, even in our own families, like, discriminations that happened in our families....

S3Fg6 [Black]: I think it's kind of unfair, cuz these are actual problems that unfortunately are still happening. Like, racism: we talked about the older days, but unfortunately it's still happening today! ... What I wanna know is, what's happening, so, what I could change? ...we should be learning about... things that are going on, so the whole world could be helping out! 


\section{Guanajuato: Prepare yourself so you can work (and stay)}

There is a stark contrast between the sense of agency and ethical-political identification expressed by the Ontario youth, and the Guanajuato youths' ways of dealing with migration conflicts in their lives. While Ontario students had strong moral judgments against antiimmigrant attitudes, Guanajuato students apparently accepted emigration as a given, something that individual people had to do, to overcome their difficult situations. They hardly ever framed emigration as an unfair consequence of unequal global relations. A couple of them denounced the treatment received by Mexicans in the USA, thereby judging the conflicts embedded in migration -similarly to students in Ontario- mainly through the cultural experience of discrimination, but downplaying the economic and political relations that reproduce marginalization and suffering.

Group 2C

E4Fg5: I think it is an injustice because Americans do not let Mexicans to go to their country, whereas they can come in and out of Mexico. Surely they despise them because they are Mexicans.

Group 3C

E5Mg5: They migrate to live better elsewhere. Sometimes they don't get that opportunity because of overpopulation and because [Americans] think they are drug traffickers, or Mexicans...

E4Mg6: Sometimes they discriminate because of the ethnicity. I we go there they would discriminate against us. ... The idea the US has of us is that we are lazy.

These young people found it difficult to imagine what they could do about the constant pressure their family members endured to leave the country. Often, this question was followed by silence until some student stated, hesitantly, that maybe citizens or the government could remind people of the importance of continuing in school in order to obtain a good quality of life (some said, a salary comparable to the United States or Canada). Students generally replicated their teachers' narratives of hard work and study as their only option in face of the migrationrelated realities they were suffering.

Group 1B

$\mathrm{E} 4 \mathrm{Mg} 8$ : We can tell them that here too, by studying, they can get the same money they make there, but putting an effort in studying and pursuing a career.

Group 3C

E4Mg5: Sometimes we do not prosper because we do what we have to and that's

it. Instead, the US and Canada are at the top because they work hard and together...

E3Fg5: We need to study more to be able to work easily and receive better wages...

E4Mg5: They need to instill in them the joy of studying and teach them the consequences of not studying. Sometimes they migrate because they are not informed. 
Despite some classroom lessons, these students had not had opportunities to make sense of the structure and politics of migration-related conflicts, beyond the individual decisions either to emigrate or to stay in school. Without the analytical tools to recognize connections among migration, economic inequality, and discrimination, young people are pushed towards accepting a political identity as the subordinate in these globalized relationships. While the Ontario students embraced the idea of being tolerant citizens of the world, the Guanajuato youth took on their status as second-class citizens - not only within their own country, but also in the world system.

\section{Discussion: Localizing the curriculum of migration}

Although all lived in marginalized communities, the migration-related experiences of student participants in Guanajuato, México and Ontario, Canada reflect their different identity positions in the global system. Guanajuato youth framed transnational emigration as a close personal problem, but did not identify actors, actions or relations capable of confronting or explaining the economic inequalities or cultural violence embedded in migration dynamics (nor what to do about them). Ontario youth recognized themselves and their neighbors as transnational immigrants, but identified only others' bad (racist) attitudes as causes of conflict. Dominant narratives reiterated by both sets of students emphasized localized cultural beliefs and attitudes as explanations of migration conflicts — not unequal identity positions in the global system - at times contradicting their own experiences.

This curriculum of migration transcending from dominant narratives tells us that we need to learn about "other's cultures" and develop a sort of cosmopolitan cultural competence. In practice, this becomes a simple reification of Other's precedencies and cultural markers that does not help to understand the connections between their sufferings and situation, and the relations we have to each other in global structures of injustices and power.

When hegemonic narratives about social justice conflicts over-emphasize a politics of cultural difference, they obscure unequal opportunities structured by the division of labor, decision making hierarchies, and institutional norms and standards existing in the world (Young 2007). We argue that, by separating localized cultural explanations of (globalized) social conflicts from their transnational structural connections, the hegemonic narratives of migration affirmed by citizenship curricula mask inequitable global relations. They end up both limiting students' sense of agency to individual, non-structural actions and reifying their identity positions in the global system.

In this way, they reproduce "a curriculum of blame", as it detaches individual actions from large-scale social processes. If migrants are uneducated, unhealthy, unemployed, or have suffered violence, is because of their life choices or their cultural background, and not because of these transnational structures and social processes. As seen in the contrasting sense of agency between Ontario and Guanajuato participants, simplified individual-cultural narratives of social conflicts may encourage political subjects to embrace - or to be (un)able to reject - unequally positioned (superior or subordinate) identities within the world system. Despite claims that globalization has made the world smaller and people more similar, we find that distances and imbalances are widened when young people view the actors and actions shaping migration conflicts as mere belief, cultural and attitude differences, versus part and product of a historically-structured unjust transnational system.

Transforming curricula about local expressions of globalized conflicts such as migration could present a significant opportunity to challenge this gap between individualized experiences 
of social conflicts and their political, structural and transnational character. Globalized migration issues curriculum could get beyond discussing the values, principles, and stereotypes that govern interpersonal and cultural interactions, and make visible the connections between personal acts and systemic consequences - thereby opening democratic space to critically question the traditions and identities that sustain systemic hierarchies in the world.

We call for a localized curriculum of migration, one that traces globalization consequences to concrete localities, to the places where the consequences of global structures' "externalities" are concretely felt. In a similar vein, a curriculum that attends to places and spaces from where you can trace concrete consequences of transnational patterns of power such as free trade agreements, border controls, and imperial and (neo)colonial wars. Localizing the curriculum of migration means that the movement of people is learned and understood as a human made process neither natural nor the responsibility of deviant individuals or "different" cultures, but as a social process where responsibilities and capacities for agency could emerge.

\section{References}

Bickmore, Kathy. (2015). Incorporating peace-building citizenship dialogue in classroom curricula: Contrasting cases of Canadian teacher development. In Régis Malet \& Suzanne Majhanovich (Eds.), Building Democracy in Education on Diversity. Rotterdam, Netherlands: Sense Publishers.

Chareka, Ottilia, \& Sears, Alan. (2005). Discounting the political: understanding civic participation as private practice. Canadian and International Education, 34(1), 50-58.

Cox, Cristián, Bascopé, Martín, Castillo, Juan Carlos, Miranda, Daniel , \& Bonhomme, Macarena. (2014). Educación ciudadana en América Latina: Prioridades de los currículos escolares. Retrieved from Geneva: http://www.ibe.unesco.org/en/services/online-materials/publications/ibe-working-papers.html

Galtung, Johan. (1996). Peace By Peaceful Means: Peace and Conflict, Development, \& Civilization. London: Sage Publications \& International Peace Research Assn.

Gordon, Daryl, Long, Jennifer, \& Fellin, Melissa. (2015). Education for national belonging: Imposing borders and boundaries on citizenship. Journal of Social Science Education, 14(3), 2 - 8.

Hughes, Andrew, Print, Murray, \& Sears, Alan. (2010). Curriculum capacity and citizenship education: a comparative analysis of four democracies. Compare: A Journal of Comparative and International Education, 40(3), 293-309.

Kennelly, Jacqueline, \& Dillabough, Jo-Anne. (2008). Young people mobilizing the language of citizenship: struggles for classification and new meaning in an uncertain world. British Journal of Sociology of Education, 29(5), 493-508.

Lederach, John Paul. (2003). The Little Book of Conflict Transformation. Intercourse, PA: Good Books.

Llewellyn, Kristina, \& Westheimer, Joel. (2009). Beyond facts and acts: the implications of 'ordinary politics' for youth political engagement. Citizenship Teaching and Learning, 5(2), 50-61.

Meyer, John W., Bromley, Patricia, \& Ramirez, Francisco. (2010). Human rights in social science textbooks: Crossnational analysis, 1970-2008. Sociology of Education, 83(4), 111-134.

Salomon, Gavriel, \& Nevo, Baruch (Eds.). (2002). Peace Education: The Concept, Principles, \& Practices around the World. Mahwah, NJ: Lawrence Erlbaum Associates.

Santos, Boaventura de Sousa (2001). Nuestra America. Theory, Culture \& Society, 18(2-3), $185-217$.

Tibbitts, Felicia, \& Torney-Purta, Judith. (1999). Citizenship education in Latin America: Preparing for the future. Washington, DC: Human Rights Education Associates.

Tupper, Jennifer, \& Cappello, Michael. (2012). (Re)Creating citizenship: Saskatchewan high school students' understandings of the 'good' citizen. Journal of Curriculum Studies, 44(1), 37-59.

Young, Iris Marion. (2007). Structural injustice and the politics of difference. In Anthony Laden \& David Owen (Eds.), Multiculturalism and Political Theory (pp. 60 - 88). Cambridge, MA: Cambridge University Press. 